\title{
Two Kinds of Economy, Two Kinds of Self-Toward More Manageable, Hence More Sustainable and Just Supply Chains
}

\author{
Carleton B. Christensen' \\ School of Philosophy, College of Arts \& Social Sciences \\ The Australian National University, Canberra, Australia
}

\section{Abstract}

Contemporary systems of production, distribution, and retail provide many end-consumers, although certainly not all, with an unprecedentedly wide choice of cheap, high quality goods and services. Yet this bounty comes at ever higher, ultimately unsustainable environmental and social cost. Something must change but what and how? Simply how production, distribution and retail are organized? Simply patterns of consumption, that is, overconsumption on the part of some, who must be convinced to consume less? Or must the target be production, distribution, retail, and consumption in their totality, that is, economic life as a whole? This paper sketches a basis and general framework for answering these questions.

\section{Introduction: The new economic order}

As Conca 2002 points out, the contemporary economic order, which offers at least some an unprecedented combination of choice, quality, and price, is only very superficially characterized in terms of 'globalization' - as if its bounty were simply the result of massively increased cross-border transactions. Whether in pursuit of competitive advantage or merely in response to competition, enterprises have used both technological innovation and political clout to create a web of supply chains characterized by what Princen (2005) has described as a logic of efficiency. This logic is an ongoing dynamic of rationalization in Weber's sense which selects for processes and procedures of greater efficiency, that is,

1 Author contact: carleton.christensen@anu.edu.au. 
processes and procedures for which the ratio of outputs to inputs is higher. As a result, the truly distinguishing feature of the new economic order has emerged: very long chains of production, distribution, and retail, often indeed spanning the globe, along which goods and services flow with increasing rapidity and with an unparalleled capacity for the rapid re-routing of these flows.

Crucially, what counts as greater efficiency at any node along a supply chain is ultimately determined by what counts as efficiency at the final node prior to consumption in the literal sense of use, namely, consumption in the economist's sense of sale. Efficiency at the retail end consists in being able to offer what the end-consumer will regard as the best possible mix of choice, price, and quality. Consequently, competition will combine with technology and politics to yield a system of production, distribution, and retail given over to optimizing for efficiency in this sense, that is, for choice, price, and quality, and this dynamic will in turn make supply chains longer, faster flowing, and more flexible.

The emergence of an economy given over to optimizing for efficiency in the sense just indicated involves a redistribution of economic power. As Conca points out, there has been a rearrangement of "the balance of power among the economic agents in a [supply] chain and between those agents and the regulatory state." This rearrangement renders:

regulatory and technological approaches to environmental protection much less effective. As a result, these traditional approaches are increasingly likely to target the weakest nodes in the chain rather than the strongest. (Conca, 2002, p. 144)

Note that the problem of regulatability to which Conca is alluding does not arise because of the international or global character of supply chains - as if international agreement or even world government could provide a regulatory or technological answer. The problem is not one of jurisdictional or regulatory reach. It is rather that contemporary supply chains have assumed a form which makes them intrinsically difficult to regulate, whatever the regulatory instance, whether a state regulating by passing and enforcing law or an individual regulating by asserting his or her will politically. ${ }^{2}$

Note further that the rearrangement of which Conca speaks involves a shift of economic power away from producers toward the retail end of supply chains. New technologies give retailers unprecedented access to a diversity of suppliers and the new politics and public policies give them unprecedented opportunities

2 That the problem is not one of (absent) jurisdictional reach, of, say, an international agreement or even world government, is shown by the fact that problems of regulatability arise even with long, highly complex and shifting supply chains within national borders. This is illustrated by the case of labor supply to the farms providing the Australian food mega-retailers with produce - see www.abc.net.au/news/2015-05-04/ supermarkets-food-outlets-exploit-black-market-migrant-workers/6441496?WT.mc_id=Innovation_News-Fo urCorners $\mid$ LabourExploitation,SlaveLikeConditionsFoundOnFarmsSupplyingBiggestSupermarkets_FBP $\mid$ abc. 
to use these technologies to play suppliers off against one another according to who can supply the higher quality at lower cost. Inevitably, in a competitive environment retailers able to exploit these opportunities will exploit them. In consequence, there arises a tendency to monopsony toward the retail end which explains the rise of the mega-retailers now found in many if not all supply chains. Mega-retailers, sometimes of global reach, now dominate numerous supply chains, for example, food, fast food, furniture, hardware, clothing, to some extent sportswear, and even bookselling. Many of these mega-retailers are retailing own brands, hence now possess product design capacity yet they do not actually produce these brands. ${ }^{3}$

Note finally that this redistribution of power toward the retail end is simultaneously an enhancement of its economic power across the supply chain. The capacity to play suppliers off against one another gives retailers the capacity to undercut their competitors in offering end-consumers higher quality at lower cost. Precisely for this reason the redistribution is a tendency to monopsony, as less-effective retailers, for example, local shop owners, fall victim to the lower prices offered by their competitors. Consequently, competition intensifies and the whole supply chain becomes explicitly organized around providing wider choice and higher quality at lower cost. As indicated above, it becomes rational in Weber's sense, that is, explicitly given over to enhancing efficiency, the ratio of outputs to inputs. And the desired output is ultimately an optimal mix of choice, quality, and cost.

Evidently, the unregulatability of supply chains entails that achieving environmental sustainability and social justice requires more than mere regulatory and technological tinkering with the current system. A radical transformation is needed. In particular, supply chains must become shorter (Renting et al., 2003), slower, and less flexible in order to make them more manageable with regard to such issues as sustainability and social justice. But what could this mean? Some think that it means going back-going back to earlier forms of economic organization, in which things did not move as far, as quickly, and as unpredictably. We must go back to more nationally and indeed locally based modes of production, distribution, and retail, hence to more nationally and locally specific modes of consumption, as exemplified by the small town economy, with its purely local stores, workshops and farms, and its slower pace of life. This will involve less choice at lower quality and higher price for consumers. But the undoing of economic rationalization will bring alternative rewards which, once tasted, will convince everyone that the renunciation was

3 Even information and communication technology is subject to such tendencies: Apple is arguably more a distributor and retailer with product design capacity than a producer. 
worth it. For these older forms of economic organization involved, or so it is thought, a degree of transparency, community, and solidarity now lost to us. Recovering this will compensate for the material sacrifice.

For two reasons such 'localist' or (bio-)'regionalist' thinking is naive. Firstly, it is not obviously true either that older forms of economic organization were more environmentally benign or that they possessed greater degrees of transparency, community spirit, and social solidarity. Certainly, they were often more racist and sexist, possibly just as ageist, and frequently small-minded. Secondly and more importantly, the current economically rationalized economic order arose out of the older forms, as individuals naively explored the possibilities of new technologies, perhaps in order to secure their own economic advantage, perhaps simply because these new technologies seemed to them to offer numerous undeniable gains without any serious losses. The older forms of organization thus lacked any institutional capacity to identify in what direction innovations and improvements in numerous undoubted goods - for example, in comfort, cleanliness, and convenience (Shove, 2003) - were taking us. Yet it is precisely this capacity one is calling for when, in response to contemporary problems of environmental destruction and social injustice, one demands a form of economic organization in which supply chains are shorter, slower, and stiffer, hence more manageable. The real problem with 'localist' or (bio-)'regionalist' thinking is thus that it does not answer the question posed by the inherent unmanageability of the new economy. Shortness, slowness, and stiffness of supply chains is merely a necessary, not sufficient condition for their manageability. One must therefore shorten, slow, and stiffen in such a way that institutional oversight is created and for this the bygone provides no model. 'Localist' or (bio-)'regionalist' thinking fails to see this.

It would, however, be equally naive simply to dismiss such thinking as entirely wrong-headed. The idea of the local is not an answer to the question of how to shorten, slow, and stiffen supply chains in a way which makes them more manageable but it does provide a clue to where one might look for an answer. The appeal to the local is in fact a muddled attempt to specify two crucial features of an answer: firstly, the kind of economic order required for manageability; and secondly, the kind of economic order which could offer such alternative rewards to beneficiaries of the current unmanageable order that they would be prepared to forgo their benefits and embrace an alternative, more manageable one.

We need, therefore, to investigate the idea of the local economy in order to determine what makes it so attractive as an answer to two problems: the problem of manageability and the problem of motivation. We may suspect that what makes the idea attractive is the perceived interrelation of these problems: what accounts for the shortness, slowness, and stiffness of highly localized supply chains is also inchoately perceived to be what accounts for those features of 
them which plausibly appear to be alternative rewards consumers could enjoy if only they renounced their current profligate ways. So we must analyze the kind of economic interaction in which individuals engage when they assume the role of consumers, retailers, and/or producers in highly localized, smallscale economies and bring out the difference when they assume these roles in the new economic order of long, fast-flowing, flexible supply chains.

\section{Thick and thin conceptions of the economy and its actor}

Supply chains are woven together by relations of exchange. Workers sell their labor time; producers sell their products; distributors, lawyers, and agents sell their services and skills; and finally retailers sell their wares to endconsumers. In the older, more local forms of economy displaced by the new economic order the exchange relation typically, if not necessarily always, takes place between individuals who live and mutually know one another to live in the same community, hence share and mutually know one another to share a common background of norms and values. This common background enables trust and goodwill, which in turn ensures good faith, at least as a rule, in the conduct of exchange, so much so, indeed, that often no explicit legal regulation is needed. As such, each party to exchange may rationally assume that, even if occasionally the other party might not desire a fair exchange, as a rule this latter does - perhaps because he or she is concerned about the longer-term damaging effects, for example, to reputation, which unfair exchange might have, but often enough simply because he or she prefers to be fair.

Such points have often been noted. Less noted, however, is the presence within such localized exchange relations of what I shall call a normatively thick conception of rational agency. In order to get at this, let us move from the real, from actual socioeconomic reality, to the ideal, the classical tradition of reflection on such reality. For a normatively thick notion of rational agency is presupposed by the classical political economists Smith, ${ }^{4}$ Ricardo, and Marx ${ }^{5}$ in their accounts of the exchange relation. When theorizing about the nature of exchange relations, such thinkers typically proceed by envisaging idealized situations, often of simple barter, in which the parties to exchange are assumed to be acting, and to mutually know themselves to be acting, in good faith. In effect, these thinkers

\footnotetext{
4 See Smith (1759/1981, II, ii, iii, p. 125).

5 It would be a misunderstanding, both of the point made here and of Marx himself, to object to Marx's inclusion here. Marx's whole point is that capitalist exchange, particularly the exchange of labor power for wages, is so to speak ontologically or structurally hypocritical. In capitalist exchange, when it is ideally functioning, both parties seek a fair exchange yet even then, indeed precisely then, distinctively capitalist exploitation (extraction of surplus value) and alienation take place.
} 
abstract from real local exchange relations, of which, of course, in their day there were many more, to an idealization thereof in order to identify the concepts and principles operative in real exchange relations.

But why do they do this? Because they believe, or rather unreflectingly assume, that the relevant concepts and principles of economics and politics can only be identified in this way. In one way, even highway robbery is an exchange relation: the robber receives money, the robbed continued life. So, too, is the situation in which sellers compel buyers to pay too much, or buyers compel sellers to accept too little. Yet classical political economy rightly regards neither highway robbery nor extortion as the kinds of exchange by studying and reflecting on which one could effectively identify the mechanisms by which markets operate, that is, prices are determined in the economy. This is not because classical political economy regards no economy as possible unless as a rule parties to exchange acted, and mutually knew themselves to act, in good faith. A general pattern or practice of human behavior such as an economic system is only possible if the individual acts in which it is realized occur as a rule, that is, according to a rule. Acts of robbery are, however, by definition exceptions to a rule. Trivially, no economy could consist of acts of robbery. The case is, however, different with extortive buying and selling. An economy is conceivable in which many, possibly even most acts of exchange were extortive. It could display some durability and resilience as a system although not as much as an economy in which most parties to exchange acted, and mutually knew themselves to act, in good faith. So an economy is possible in which parties to exchange did not act, and did not mutually know themselves to act, in good faith.

So when classical political economists assume a concern for fairness in the idealized depictions of exchange from which they extract economic concepts and principles, they are not thinking of the economy as a system which requires for any kind of durability and resilience that its component acts be conducted as a rule in a spirit of fairness. They in fact have a deeper reason for their assumption. From the outset, they assume that the point of economic activity, hence of exchange, is not simply to service the needs and desires, whatever they might be, of economic actors, but rather to contribute to the existence of these latter as free rational agents, respected as such by others. Economic interaction is understood from the outset as given over to serving the legitimate needs and desires of economic actors for whom being fair is a value in and of itself, indeed a value most mostly adhere to.

In other words, the classical political economists assume from the outset that economic interaction possesses those general patterns of behavior which make it a possible object of study for them by virtue of its being essentially oriented not simply toward satisfying human need and desire but toward enabling human beings to exist most fully as the self-conscious, rational beings they 
essentially are - as what Kant calls ends in themselves. In this sense, they are assuming a normatively thick concept of economic life and interaction. And in assuming this, they are assuming a correspondingly thick concept of the human beings who participate in such life and interaction. Human beings are understood to be rational agents, that is, beings condemned by natureby their nature - to satisfy need and desire by use of reason. But for the classical political economists this understanding goes hand in hand with another: that human beings are rational agents is understood to mean that they are also moral agents, that is, beings who (a) understand what it is to be fair and equitable in one's dealings with others and that one is morally required to be so, and (b) are as a rule concerned to be so, typically because one is morally required to be so. For classical political economists such as Marx, Ricardo, and Smith, it is constitutive of being a rational agent that one can understand and apply moral concepts in moral judgments and that as a rule-psychopaths are, of course, an exception - one has a sense of decency and self-respect which makes one capable of conscience, shame, and guilt. The idealized economic actor one must presuppose in order to understand economic order is someone who from the outset prefers to do the right thing and, at least as a rule, actually does the right thing.

Not by chance, then, do the idealized exchange relations described and elaborated particularly by Smith and Ricardo look like the kinds of exchange relation one finds in small-scale economies - relations one has to the butcher, baker, and candlestick maker. Both the idealized exchange relations of politically economic theory and the real ones of a highly localized, small-scale community, for example, a small country town, tacitly presuppose a certain conception of what the individual at least ideally is who enters into an exchange relation with another. Parties to exchange are assumed to be rational not just in the sense of being able to order courses of action according to the degree to which these courses of action are desired or preferred. They are assumed to have more structure than this. In particular, the desires of each party to exchange are assumed to be governed, and known by the other party to be governed, by a master desire to act fairly and equitably-provided, of course, that the other party can be relied upon similarly to act fairly and equitably. In short, as a selfconscious, rational agent, any party to exchange is willing, and is understood by the other to be willing, to do the right thing by the other, at least as a rule if not always; each is willing, and is understood by the other to be willing, to temper private or personal interest ${ }^{6}$ by considerations of fairness - a willingness grounded in respect for the other as deserving of fair treatment.

6 Private or personal interest must not be identified simply with self-interest. A private or personal interest need not be selfish but rather, say, an interest in the good of one's children or even an interest in an ethical cause to which one is personally committed. 
Moreover, the reason why in both the idealized cases considered by classical political economy and real cases of local exchange this richer, indeed somewhat Kantian conception of self is presupposed is the same: de facto the same understanding of the point and purpose of exchange is operative, namely, that it is there to permit decent people to live decently. So in both theory and reality the assumption is that the defining point of exchange and of economic interaction generally is to enable beings prepared to give others their due to receive their due, hence to receive some fair degree of desire-satisfaction, that is, to have, as far as possible, their legitimate desires and preferences satisfied. Economic interaction takes place not just to ensure efficient allocation of resources, and thereby efficient satisfaction of desire. Rather, it takes place in order to enable those who participate in it to be happy without doing wrong and to do right without being unhappy - to live well in Aristotle's sense.

This is a crucial result. For what conception of the rational agent is implicit in the kinds of exchange relation which have displaced the highly localized kind? Let us consider, in particular, the retail exchange relation since as we have seen retailing has become so powerful in the new economic order. Mega-retailers have replaced the friendly neighborhood grocer and hardware shop owner because they are more competitive with regard to choice, price, and quality. They are more competitive because they have greater capacity to shop around for suppliers who can offer them wider choice, lower cost and/or higher quality, which they can then pass on to their customers. Thereby they progressively select for retail exchange relations which are no longer embedded in and carried by any common community or background familiarity between buyer and seller. In this sense, the retail exchange relation has been rendered purely efficient, purely a means-ends transaction.

Evidently, this development leads to retail exchange relations which are now as a rule, and not just as an exception, impersonal and unfamiliar - the kind of retail exchange relation which late modern shoppers experience as they push their shopping trolleys around the mega-retail outlet. Note, however, that corresponding to this development is a shift in how both the rational agent, whether buyer or seller, and economic life and interaction in general are understood. In selecting for economically rationalized, more efficient exchange relations, economic competition also selects for new conceptions of the economic actor, that is, of the economically rational agent and of economic life and interaction in general. In one's role as an economic actor, that is, when taking part in the exchange relations which hold supply chains together, in particular, retail exchange relations, one is acting as a rational agent if and only if one subjects a range of prima facie desirable actions to a cost-benefit analysis through which one orders them according to how efficiently they are realizable. In this picture, then, economic actors are not to assumed to have as a rule a master 
desire to act, or preference for acting, fairly and equitably which constrains this cost-benefit analysis. Relatedly, the economy is understood to be a domain of interaction given over simply to satisfying need and desire effectively or, as it is more usually put, to allocating resources efficiently.

In short, in selecting for new, economically rationalized exchange relations, the logic of efficiency selects for a new conception of what it is for human beings to comport themselves rationally in exchange relations, hence of what the economy ideally accomplishes, given this economically rationalized conception of the economic actor. Clearly, these new conceptions correspond well to how the economic actor and the economy are conceived in much of the economic theory which has superseded classical political economy. But what is the practical and political significance of these points, particularly with regard to the issue of how supply chains might be shortened, slowed, and stiffened in way which addresses both the problem of manageability and the problem of motivation?

\section{Breaking the hegemony of the economic}

If the source of unsustainability is ultimately an economic system given over to the pursuit of efficiency for the sake of ever wider choice, ever higher quality, and ever lower price, then what must change is the system as a whole. It will not do simply to target production, distribution, and retail exchange, as if technoregulatory solutions involving no change in levels of consumption sufficed. ${ }^{7}$ Nor will it do simply to target consumption, as if exhortation about the imprudence and injustice of current consumption ${ }^{8}$ sufficed. Such exhortation would provide no guidance as to how the beneficiaries of current patterns of consumption could live well in a radically more sustainable and more just way and so, because no radically more sustainable and radically more just social order can be imposed upon these beneficiaries, it would be pointless. Those who currently benefit must be offered a genuine alternative, one which could make them want social transformation toward significantly greater sustainability and social justice because it enabled them themselves to live well, perhaps indeed better.

This imposes a strong condition of adequacy on any putative solution to the interconnected problems of unsustainability and social injustice. Achieving sustainability and social justice requires that supply chains be made more manageable, hence shorter, slower, and stiffer. But the considerations just adduced show that such shortening, slowing, and stiffening will mean less choice, lower quality, and higher price. In other words, it will deny consumers,

7 As Hawken et al. (1999) believe. For all the rhetoric about a radically new approach to design, natural capitalism remains firmly focused on the production side alone.

8 As exemplified by Ewen (1976), Schor (1998), Hamilton and Denniss (2005), and many others. 
particularly but not exclusively in the First World, a considerable slice of the benefits they currently enjoy. Consequently, no such shortening, slowing, and stiffening will be viable in the long term unless, in addressing the problem of manageability, it also addresses the problem of motivation. The solution to the problem of manageability must therefore also plausibly constitute a solution to the standing problem of human existence, namely, how to live well.

But what has made supply chains so long, fast flowing, and flexible is the relentless dynamic of rationalization according to criteria of efficiency. So one part of the solution to the problem of motivation will consist in showing that and how this dynamic impacts negatively upon all dimensions of life. Specifically, it must be shown that and how it distorts the realization of what economic actors essentially are on the thick conception of them, namely, finitely rational agents, in other words, rational animals in a recognizably Aristotelian sense, essentially oriented toward living not just happily and not just virtuously, but both simultaneously - toward living well. Evidently, this is to assume that the thick conceptions of the economic actor, hence of the economy, are correct. But if this assumption is correct; and if it can be shown that and how the hegemony of the economic distorts the realization of the thick conceptions, then one will have shown that and how an economic order subject to unceasing economic rationalization tends toward dissatisfaction and indeed unhappiness even for those who benefit materially from it.

The other part of the solution to the problem of motivation would consist in showing that and how the putative solution to the problem of manageability better realizes the regulative ideal of living well, understood as a life of contentment because in it justice and personal happiness are unified. Evidently, here, too, the assumption is operative that the thick conceptions of the economic actor, hence of the economy, are correct. But if they are correct, then the putative solution to the problem of manageability would have been shown to be a genuine, that is, genuinely motivating alternative to the current economic order, even for those who currently benefit from the latter. The problems of manageability and of motivation would have been, as required, simultaneously solved.

Clearly, accomplishing all this cannot be undertaken in this paper, not the least because it would involve validating the thick conceptions of the economic actor and the economy. For this reason, I will in the next section simply make some suggestions as to the general form a solution to the problem of manageability would take, intimating along the way how, under the assumption that the thick conceptions are correct, this solution also solves the problem of motivation. Then, in conclusion, I will intimate how one might make good this assumption. 


\section{The politicization and democratization of supply chains}

Let us consider one particular supply chain, namely, the food supply chain, as a case to work from. This supply chain is chosen not just because it constitutes a good example but because when one works with thick conceptions of the economic actor and the economy it turns out to be a fundamental one, that is, at the very core of an economy whose defining purpose is to enable finitely rational beings to live well. Other examples of core supply chains would be education, health, and housing. The basic principle governing the effort to make food supply chains manageable is that the end-consumer, retailer, and producer should become, precisely in their roles as end-consumer, retailer, and producer, political. More precisely, supply chains must be structured in such a way that individuals in them, in their roles as end-consumer, retailer or producer, can collectively determine, in political fashion and according to political criteria, e.g., criteria of sustainability and justice, how the supply chain functions. What would this look like in our representative case of the food supply chain?

We should start with phenomena to which environmentalists already appeal as presaging new practices of food production, distribution, retail, and consumption in the literal sense. Around the world diverse efforts are being made to find alternatives to the existing system of industrial agriculture, from farmers' markets through community gardens to urban and labor-intensive agriculture which bring people back to the land. Possibilities for small-scale, labor-intensive food production, both in urban, suburban, and rural contexts, need to be explored. This would require development of arguments against urban consolidation, which is frequently and often disingenuously promoted as a strategy for sustainability. In particular, these efforts need to recognize an underlying, unifying goal: blurring the distinction between city and country, in an effort to keep people on land and land around people. To this end, strategies of decentralization and distribution of the population through the landscape, connected by rapid mass transit, would be needed.

Farmers' markets should, of course, be promoted since they bring urban end-consumers into face-to-face contact with food producers. At the same time, it must be acknowledged that farmers' markets are relatively superficial phenomena: not only are many of the products currently sold at such markets indistinguishable in terms of their sustainability from what one can buy in a conventional supermarket, the knowledge they impart of food production is actually minimal. Nonetheless, they could provide an important line of communication between end-consumers and producers on the basis of which, given the right support, more ambitious measures could be grounded. Thus, the 
contact they enable could be utilized for creating arrangements of mutual support between rural and urban communities. This could lead to arrangements with urban residents and municipalities which give farmers access to urban green space in order either to produce themselves or to mentor urban residents in urban agriculture. Conversely, it could lead to arrangements where urban residents work part time or casually in rural production in return for produce.

But perhaps most significant would be the idea of extending aspects of the principle of food consumer cooperatives to standard food retail. The idea behind this would be to exert pressure on standard food retail from both ends of the supply chain, from the producers and the end-consumers. One could imagine representative bodies of producers and end-consumers jointly insisting, from opposite ends of the supply chain, on certain kinds of environmentally friendly and socially just retailer behaviors. Goals would not be restricted to such low hanging fruit as bans on plastic shopping bags, palm oil products, and excessive packaging. Ideally, one would seek to empower end-consumers and producers to work with retailers, beginning at the local level, in order to change the character of retail itself. For example, consumer representatives might insist that there be greater representation of bulk ingredients for preparation at home rather than highly processed dishes for the microwave, that products be sourced locally, and that less emphasis be placed on highly packaged individual portions.

The impacts of these changes would begin in patterns of consumption (in the literal sense) and ramify down the supply chain to producers. In particular, they would mean more retail handling and serving; even checking out would take longer so retailers would be less able to push customers through their stores. Such inefficiencies would contribute significantly to shortening, slowing, and stiffening supply chains. But these impacts would engender other environmental and social goods currently sacrificed at the altar of efficiency. For example, there would be a considerable reduction in the use of plastic, something which would itself contribute to shortening and slowing supply chains since plastic packaging is essential for transporting produce over long distances, for moving goods quickly, and for the individual portions which make self-serve possible. The impacts would thus extend to the very layout and look of retail outlets: less freezers and shelves, more counters and staff. Last but not least, these changes would reduce retail choice since retail choice is not simply a function of how many suppliers a retailer can access but also of packaging and portioning: without plastic packaging and individual portions it becomes harder to offer many brands of the same kind of product.

Of course, in order to accomplish this, there would have to be a significant reorientation in the understanding of commercial enterprise. The idea that companies exist simply in order to enhance shareholders' value would have to be renounced. This would in turn require a change in the culture of investment, 
away from the idea that investment is simply a way of using capital to generate more capital. Alternative forms of commercial enterprise would therefore have to assume a larger role, for example, producer and retailer cooperatives alongside the cooperatives of end-consumers already mentioned. ${ }^{9}$ Their economically cooperative rather than competitive goals make cooperatives more likely to embrace ethical constraints on capital accumulation. A development of the idea of a cooperative would be to extend the already familiar idea of, for example, food consumer cooperatives to include selected producers in a single cooperative body. End-consumers could thereby help producers in the distribution and retail of produce while producers could respond directly to consumer concerns about food quality and environmental and social issues generally. In addition, cooperatives involving urban end-consumers and rural producers would facilitate the extension of production into urban landscapes and, conversely, the engagement of urban end-consumers in production. Nor need the producers be strictly local; one could imagine First World consumer cooperatives linking up with producer cooperatives in the Third World in the name of fair trade.

Evidently, any such politicization and democratization of the food supply chain would require end-consumers, retailers, and producers alike to think and act ethically, not just prudentially, when performing their respective roles within the supply chain. So the implementation of strategies for a more political and democratic food supply chain would lead to the chain's adapting to 'fit' the kind of economic actor which enacts it: just as the current supply chain maintains and is itself maintained by economic actors thinking and acting in terms of what most effectively and efficiently realizes their individual desires and preferences, so, too, a transformed, politicized and democratized supply chain would maintain and be itself maintained by economic actors who think and act in the light of a common interest in a supply chain which delivers produce at acceptable levels of choice, quality, and price while being constrained by considerations of sustainability and social justice. In short, the supply chain comes to implement the thick conception of the economic actor qua finitely rational agent.

Furthermore, if, as I am tacitly assuming, the thick conception is correct, then a politicized and democratized food supply chain will, given sufficient visceral experience of and habituation to it, appear more desirable than one which operates simply according to criteria of choice, quality, and price for the consumer. For rational agents in the thick sense have a concern to do the right thing which makes them able to moderate the satisfaction of their desires and preferences once they become aware of others to whom they harbor no ill will who would suffer if they pursued desire-satisfaction simply according

9 An interesting example of this is the Earthworker Cooperative in the Latrobe Valley of Victoria, Australia - see http://earthworkercooperative.com.au/. 
to criteria of what desires and preferences they can effectively realize in the circumstances and how efficiently. This concern is all the more effective in moderating the satisfaction of desire and preference the more individual consumers are supported by and work together with other actors in the supply chain. For this reason, it is crucial that the alternative supply chain envisaged have mechanisms embedded in it which support solidarity and communication along it. For the capacity to create and maintain such support is an essential component of the capacity to provide the alternative rewards which make the alternative supply chain more desirable in the longer run. In other words, such support mechanisms are an essential part of the alternative rewards which would compensate for narrower choice, lower quality, and higher price, in particular, for more frequent unavailability, increased seasonality, and greater regionality.

Last but not least, politicization and democratization of the food supply chain would require that people have more time to think and act more reflectivelyeven at the cost of what, by current standards, would count as inefficiency. It would thus be essential to break with the tendency of the current economic order to subordinate time to its imperatives. For most people this is experienced as the primacy of work: no time off from work, whether merely for rest and recreation; for familial, social, or political engagement; or indeed for reflective thinking about the point and purpose of time on is sacrosanct. If the economy requires it, then these activities and the socially appointed times for and durations of them must be renegotiated. Thus, the weekend in the sense of a socially appointed period during which all regular work ceases in order that there might be collective time off for collective non-work activity is increasingly undermined. Increasingly, indeed, one must be prepared to work whenever required during the day; other activities must be rescheduled to fit. Increasingly, too, one is expected to move to where the work is, even to relocate when work relocates. Sometimes one must be prepared to travel thousands of miles to work, hence be absent from one's family, friends, and community for several weeks on end, as illustrated by the fly-in/fly-out workplace.

The subordination of time to economic imperatives undermines the capacity to act freely and think reflectively. Thus, one would prefer to use environmentally friendlier public transport but must choose to use the private car because one's schedule is so tight and fragmented vis-à-vis the schedules of others. Moreover, the increasingly individualised character of work induced by its increasingly temporally and geographically fragmented character gives individuals less opportunity to reflect collectively with others, which is the process through which one best learns how to compare one's own needs and desires with those of others, hence to moderate the former in the light of the latter. The capacity of individuals to gain critical distance to their needs and desires is thus impaired, such that it becomes harder for each to say, "I thought I really wanted that but 
now I see that I can go without it." In general, when temporal and geographic fragmentation forces individuals back upon themselves, their wants becomes less negotiable, so to speak less fungible, and so it becomes harder to envisage and accept alternatives. Lastly, it becomes harder to reflect meaningfully on what the nature of one's work is and on what effects it is having on oneself and one's society.

A food supply chain defined by a concern not simply to optimize for choice, quality, and price but also and primarily to constrain such optimization by considerations of sustainability and justice could not afford such truncation of practical reason. It therefore cannot operate at such speeds that practical deliberation is impeded in the ways indicated. In particular, a politicized and democratized food supply chain would positively require individuals to have time and capacity to reflect on what the effects of work and of the economy in general are and especially on whether, as currently organized, work and the economy serve the purpose of economic life adequately. Work would thus be regulated in its speed and flow by the requirements of such reflection rather than the other way around.

This is a crucial point: a politicised and democratised food supply chain would involve end-consumers, retailers and producers working together to determine the operation of the entire supply chain. The supply chain must therefore have the capacity to allow time off from regular work activity in order to participate in oversight of other nodes in the chain. Similarly, end-consumers whose regular work activity occurs in other supply chains would have to have time off from their own work activity in order to be able to participate in the regulation of the food supply chain. Naturally, the converse would also apply: end-consumers must be able to choose to participate in the regulation of (aspects of) other supply chains. This does not entail, of course, that everyone must be involved in every supply chain in which they participate, either as producer, retailer or endconsumer; this would be absurd. But it does entail that the pace and character of all supply chains must be such as to permit individuals to choose to participate in the regulation of a given supply chain if they want to do so. The food supply chain and supply chains generally must have the freedom and capacity to offer participation at different points along them. This would require a much more leisurely pace for supply chains overall. 


\section{Conclusion: A critically theoretic interdisciplinary research agenda}

Clearly, implementing ideas such as those outlined in the previous section would amount to a radical transformation - all the more so when one considers that one cannot change the food supply chain in accordance with them without changing all supply chains in their totality, that is, the whole economy. All the greater is the need, therefore, for substantial empirical research. For example, it would be crucial to investigate the issue of just how much and in what way urban agriculture could contribute to food production in advanced capitalist countries. Relatedly, it would be essential to investigate whether and to what degree agriculture in general can and should be rendered more labor intensive: contemporary capital-intensive agriculture only achieves its great labor efficiencies on the basis of cheap energy, both for fuel and for fertilizer, and the current source of this, oil, is running out with no substitute in sight. Moreover, there are many social and political benefits to be had from increasing the labor intensity of the economy: provided it can be done without impoverishing people materially or culturally, more labor-intensive agriculture would revitalize regions and reverse the depopulation of city hinterlands. One starting point for such empirical investigation would be the literatures on urban agriculture, ${ }^{10}$ the "new peasantries" (van der Ploeg, 2009), and the Cuban experience (Premat, 2009) because these provide evidence that labor-intensive and small-scale urban agriculture can make a genuine economic contribution in some areas even if some activities, for example, grain production, must always require non-local or large-scale broad acre farming (see Dyball \& Newell, 2015, pp. 194-195).

Further empirical and theoretical research would be required in order to investigate how other supply chains might be politicized and democratized, for example, furniture and hardware. Such politicization and democratization would potentially be far more effective than certification or even producer-responsibility legislation in monitoring the harvesting of timber and the materially intensive production of low-price but low-quality tools which rapidly end up in landfill. Moreover, the idea of extending principles developed for the representative case of the food supply chain to other supply chains provides an opportunity for addressing a crucial theoretical issue in radical environmental politics. As already intimated, it need not and indeed cannot be the case that all individuals will be involved in all supply chains in which they appear as either producer, retailer, or end-consumer. This suggests that the politicization and democratization of supply chains enables a kind of social engagement and solidarity which is not

10 See, for example, www.sustainable-everyday-project.net/urbact-sustainable-food/. 
totalizing in the manner implicit in much green romanticizing about community and direct democracy. For it is a conception of highly local, direct democratic engagement which is not concerned with the affairs of the whole but merely with those of that aspect of the supply chain in which a citizen happens to be interested. The picture painted here is thus not of all citizens gathering together in order to decide, in direct democratic fashion, the affairs of society as a whole. As far as the political sphere is concerned, this can remain representatively democratic and therefore a domain protective of standard liberal rights, up to and including the right not to be involved, that is, to be a purely private citizen. The politicization and democratization of supply chains would be consistent with a less emphatic, low key kind of social solidarity and support, along the lines of what Miller and Woodward (2012, p. 10) call the silent community. This more modest form of community is arguably more practically consistent with the reality of mass society and more ethically consistent with modernity's distinctive emphasis on individual autonomy.

There is also a necessary philosophical dimension to the theoretical research clearly required by the idea just sketched of politicizing and democratizing supply chains. For the thick conceptions of the economic actor and the economy presupposed by this idea require justification. At first, one might think that such justification is a perfectly empirical issue. Has not much recent empirical investigation shown or at least strongly suggested that many human beings, although certainly not all, have a propensity to act in a spirit of fairness if others act similarly; and that in general they bear goodwill to others, at least within certain bounded domains of familiarity? (See, e.g., Fehr \& Fischbacher 2003.) Why, then, should any distinctively philosophical grounding of this conception be needed?

Empirical investigation can certainly show that many or even most human beings incline to fairness and goodwill, just as it can show that many or even most swans are white. But the thick conception of the economic actor qua rational agent makes a claim stronger than this. It is not simply a statistical claim to the effect that, as a matter of brute fact more than fifty percent of human beings incline to fairness and goodwill. Rather, it claims that humans do so as a rule. This means that although there certainly are some humans who are not thus inclined, these individuals are derivative upon rest-derivative in the sense that they are exceptions which presuppose, hence prove the rule. That is, in a sense which must, of course, be further specified, an individual can only exist as not inclined to fairness and goodwill because and insofar as there are others who are thus inclined. The thick conception asserts something which cannot be established in the empirical fashion in which one establishes that many or most swans are white or indeed that many or most humans incline to fairness and goodwill. 
But now one might ask whether the thick conception is needed at all. Perhaps from the strictly practical point of view of the environmental activist all one needs is simply the weaker general claim that many people are inclined to be fair and display goodwill. Is this not enough to work from in the effort to reorder the economic order away from its orientation simply toward providing goods and services as efficiently as possible? No, it is not enough; the necessity expressed by the claim that humans as a rule are disposed favorably toward the right and toward others is essential because it permits one to argue that all possible human beings and not just certain actual ones are as a rule oriented toward living well, hence not toward unconstrained desire-satisfaction. Thereby it permits one to argue that even those who deny the claim that human beings are as a rule oriented toward living well, indeed even those whose behavior contradicts it, are not truly happy even though they feel perfectly comfortable, have lots of pleasant experiences and few painful ones. Consequently, the thick conception, when justified, gives one confidence that in the long run anyone who is fully and sufficiently rational could be brought by argument or personal experience to acknowledge that the claim is right and that they would be happier if their lives, as agreeable as they currently are, could also be that much more ethical without (significant) loss. This points to a powerful result: precisely in order for it to provide a rational basis for activists to believe that beneficiaries of the current economic order can be rationally brought to regard, indeed to experience, their current life as suboptimal, the thick conception must be understood to be truly and irrevocably philosophical, such that it can only be justified philosophically.

Actually providing this philosophical justification would require some heavy duty philosophy which cannot be undertaken here. Arguably, however, it would take Kantian form. That is, in order to establish the crucial conceptual link between rational and moral agency in which the thick conception consists, one would seek to show that the capacity for first-person thinking presupposed by the concept of rational agency - the capacity to think, for example, "I am 6 foot tall" or "I see Mount Everest" - requires a unity of the self which does this thinking that is only possible if this self has an understanding of who and what it is, an understanding which involves a grasp of itself as measuring up, to one degree or another, to norms and values that matter to it. It thus does not just have knowledge of norms and values, it cares about them, hence suffers guilt and shame insofar as it fails to live up to them. In particular, it possesses some degree of self-respect and self-esteem. If, however, this is so, then underpinning all explicit commitment to the concrete norms and values of one's epoch, culture, peer group, etc., there is implicit commitment to a principle of fairness and equity. With this, we have reached the thick conception of the finitely rational agent. 


\section{References}

Conca, K. (2002). Consumption and environment in a global economy. In T. Princen, M. Maniates, \& K. Conca (Eds.), Confronting consumption (pp. 133-153). Cambridge, MA: The MIT Press.

Dyball, R., \& Newell, B., (2015). Understanding human ecology: A systems approach to sustainability. London: Earthscan.

Ewen, S. (1976). Captains of consciousness: Advertising and the social roots of the consumer culture. New York: McGraw-Hill.

Fehr, E., \& Fischbacher, U. (2003). The nature of human altruism. Nature, 425, 785-791.

Hamilton, C., \& Denniss, R. (2005). Affluenza: When too much is never enough. Crows Nest, NSW: Allen \& Unwin.

Hawken, P., Lovins, A., \& Lovins, L. H. (1999). Natural capitalism: Creating the next industrial revolution. New York: Little, Brown and Company.

Miller, D., \& Woodward, S. (2012). Blue jeans: The art of the ordinary. Berkeley, CA: University of California Press.

Premat, A. (2009). State power, private plots and the greening of Havana's urban agriculture movement. City \& Society, 21(1), 28-57.

Princen, T. (2005). The logic of sufficiency. Cambridge, MA: The MIT Press.

Renting, H., Marsden, T., \& Banks, J. (2003). Understanding alternative food networks: Exploring the role of short supply chains in rural development. Environment and Planning A, 35(3), 393-411.

Schor, J. B. (1998). The overspent American: Upscaling, downshifting, and the new consumer. New York: Basic Books.

Shove, E. (2003). Comfort, cleanliness and convenience: The social organization of normality. Oxford: Berg Publishers.

Smith, A. (1759/1981). The theory of moral sentiments. D. D. Raphael \& A. L. Macfie (Eds.). Indianapolis, IN: Liberty Fund.

Van der Ploeg, J. D. (2009). The new peasantries: Struggles for autonomy and sustainability in an era of empire and globalization. London: Earthscan. 
This text is taken from Human Ecology Review, Volume 21, Number 2, 2015, published 2015 by ANU Press, The Australian National University, Canberra, Australia. 